\title{
Effect of CPP-ACP on remineralization of artificial caries-like lesion: an in situ study
}

\author{
Patrícia Regina Almeida de \\ OLIVEIRA $^{(a)}$ iD \\ Caroliny Mello BARBOZA(a) iD \\ Luísa Schubach da Costa \\ BARRETO(a) iD $^{(a)}$ \\ Mônica Almeida TOSTES(a) iD \\ (a) Universidade Federal Fluminense - UFF, \\ School of Dentistry, Department of Pediatric \\ Dentistry, Niterói, RJ, Brazil.
}

Declaration of Interests: The authors certify that they have no commercial or associative interest that represents a conflict of interest in connection with the manuscript.

\section{Corresponding Author:}

Monica Almeida Tostes

E-mail: matostesuff@yahoo.com.br

https://doi.org/10.1590/1807-3107bor-2020.vol34.0061

Submitted: March 2, 2020

Accepted for publication: April 20, 2020

Last revision: May 19, 2020

\begin{abstract}
The purpose of this double-blind, randomized, crossover in situ study is to compare remineralization of preformed enamel lesions by casein phosphopeptide-stabilized amorphous calcium phosphate (CPP-ACP) and fluoride dentifrice products. During each of four 10-day experimental legs, 10 participants wore intraoral removable palatal acrylic appliances with four human enamel slabs with preformed lesions. A $0.03-\mathrm{mL}$ treatment paste was dripped extraorally onto the enamel blocks once a day for $3 \mathrm{~min}$. The four randomly allocated treatments were as follows: CO- Control: silica dentifrice without fluoride; MP: MI Paste; MPP: MI Paste Plus and FD: Fluoride dentifrice - 1100 ppm F as NaF). Knoop surface hardness (SH) test was performed in three stages (T0 - sound enamel, T1 - after preformed lesion, and T2 - after treatment) and the cross-sectional hardness (CSH) test was performed after treatment using a 50-gram Knoop load for $15 \mathrm{~s}$. Knoop hardness number $(\mathrm{KHN})$ was similar between treatments. \%SHr was significantly higher in the MP, FD, and MPP when compared to CO group (Kruskal-Wallis and Mann-Whitney tests, $\mathrm{p}<0.05$ ). Harder enamel was found in MP $(75 \mu \mathrm{m})$ and FD groups at 75 to $175 \mu \mathrm{m}$. Treatment with DF, MP, and MPP promoted an increase of $20.27 \%$, $19.24 \%$, and $14.71 \%$, respectively, in Integral Hardness Change ( $\triangle \mathrm{IHC})$ when compared to $\mathrm{CO}(\mathrm{p}<0.05)$. Remineralizing agents (MP, MPP, and $\mathrm{DF})$ were able to inhibit demineralization of human enamel subjected to high cariogenic challenge in situ. DF had the greatest preventive potential against the progression of carious lesions.
\end{abstract}

Keywords: Dental Enamel; Fluorides; Hardness Tests;

Tooth Remineralization.

\section{Introduction}

Casein phosphopeptide-stabilized amorphous calcium phosphate (CPP-ACP) is reported to have topical anticariogenic effects owing to its ability to stabilize calcium and phosphate in an amorphous state. ${ }^{1}$ Reynolds et al. ${ }^{2}$ show that not only does CPP increase fluoride incorporation into biofilm, but it also increases the incorporation of fluoride into subsurface enamel and substantially increases remineralization of enamel subsurface lesions when compared with fluoride alone. In a recent study, bioavailable calcium levels have been significantly correlated with enhanced 
remineralization of enamel subsurface lesions. ${ }^{3}$ The presence of saliva and biofilm is indispensable for the mechanism of action of CPP-ACP. ${ }^{4}$ In an acidic environment, ACP separates from CPP, thereby increasing salivary calcium and phosphate levels. ${ }^{3,4}$ CPP can stabilize the level of ACP in the saliva by preventing precipitation of calcium and phosphate, and can stabilize calcium levels. ${ }^{5} \mathrm{CPP}-\mathrm{ACP}$ localizes $\mathrm{ACP}$ in the dental biofilm, buffering free calcium and phosphate ion activities and helping stabilize the level of ACP in the saliva, maintaining an amorphous state of supersaturation with respect to tooth enamel, depressing demineralization and enhancing remineralization..$^{6,7}$ Lower adherence of microorganisms has been observed after incorporation of CPP into the salivary pellicle, in addition to delayed oral biofilm formation and maturation. ${ }^{8}$

In vitro enamel remineralization models have been widely used for predicting the anticaries efficacy of CPP-ACP, $9,10,11,12,13,14,15$ but several questions about the remineralizing effects of $\mathrm{CPP}-\mathrm{ACP}$ remain unanswered. The preventive potential of CPP-ACP has been observed in in situ human models, showing significant remineralization of enamel subsurface lesions. ${ }^{3,4,7,15}$ In situ models are more realistic, but they must be very carefully designed to assess the ability of remineralizing agents so as to minimize the confounding effects of many variables involved. ${ }^{16}$ Thus, fluoride availability from the brushing of natural teeth can be a confounding factor. This residual fluoride present in the saliva after brushing probably reflects the slow elimination of fluoride from intraoral reservoirs, such as biofilms. ${ }^{16,17}$

Further studies are needed to obtain more information about the remineralization process when fluoride and CPP-ACP are used in a randomized, controlled, double-blind trial. The aim of the present study is to evaluate the remineralization potential of CPP-ACP crèmes and to compare it with that of fluoride dentifrice products in artificial lesions on enamel surfaces using surface microhardness $(\mathrm{SH})$ and cross-sectional hardness (CSH) as parameters in a randomized, controlled, double-blind, crossover in situ model. The null hypothesis was that remineralizing agents such as fluoride dentifrice (FD), MI Paste (MP), and MI Paste Plus (MPP) would not result in greater remineralization in artificial caries compared to a placebo (dentifrice without fluoride) in an in situ model.

\section{Methodology}

\section{Experimental design}

This study was approved by the local Human Ethical Committee (process 411.762). The study was conducted in accordance with the Declaration of Helsinki. This was a double-blind crossover in situ study performed in four phases with a length of 10 days each.

\section{Sample preparation}

Enamel blocks (from human molar teeth) were sequentially polished and selected according to the $\mathrm{SH}$ test results. Blocks were demineralized and subjected to post-treatment in the in situ model (Figure 1). In this study, human third molars, which had been extracted for surgical reasons, were used. The samples were free of caries, of fluorotic or hypomineralized lesions, and of any other visible defects. The teeth were stored in $0.1 \%$ thymol during the sample preparation process. A total of 160 enamel blocks were obtained from the buccal and lingual surfaces of 80 third human molars. After fixing the blocks in acrylic resin, the buccal surfaces of the enamel specimens $(3 \times 3 \times 3 \mathrm{~mm})$ were ground with $\mathrm{SiC}$ paper $(400,600$, and 1,200 grit; Struers, Copenhagen, Denmark) to obtain flat surfaces. The specimens were then polished using a 1- $\mu \mathrm{m}$ diamond polishing suspension with a polishing cloth (Arotec Ind \& Com, Cotia, Brazil). The baseline $\mathrm{SH}$ of all specimens was measured using a microhardness tester (Micromet 2001, Buehler, USA) with a Knoop diamond indenter under a 50-gram load for $15 \mathrm{~s}$. Five indentations, spaced $50 \mu \mathrm{m}$ apart, were made, and the mean values of enamel surface hardness were calculated (baseline $\mathrm{SH}=\mathrm{T}$ ). . A total of 160 specimens with a mean $\mathrm{SH}$ value of $326.32 \pm 38.12$ was chosen. The enamel blocks were distributed into four groups of 40 blocks each: MI- MI Paste (Recaldent ${ }^{\mathrm{TM}}$ - GC Corporation, Tokyo, Japan); MPP - MI Paste Plus (900 ppmF; Recaldent ${ }^{\mathrm{TM}}$ - GC Corporation, Tokyo, Japan; FD - Crest ${ }^{\mathrm{TM}}(1,100$ ppmF; Colgate-Palmolive Ltda., São Bernardo do Campo, Brazil); and CO - Dentifrice without fluoride (Daudt Ltda, Rio de Janeiro, Brazil). 


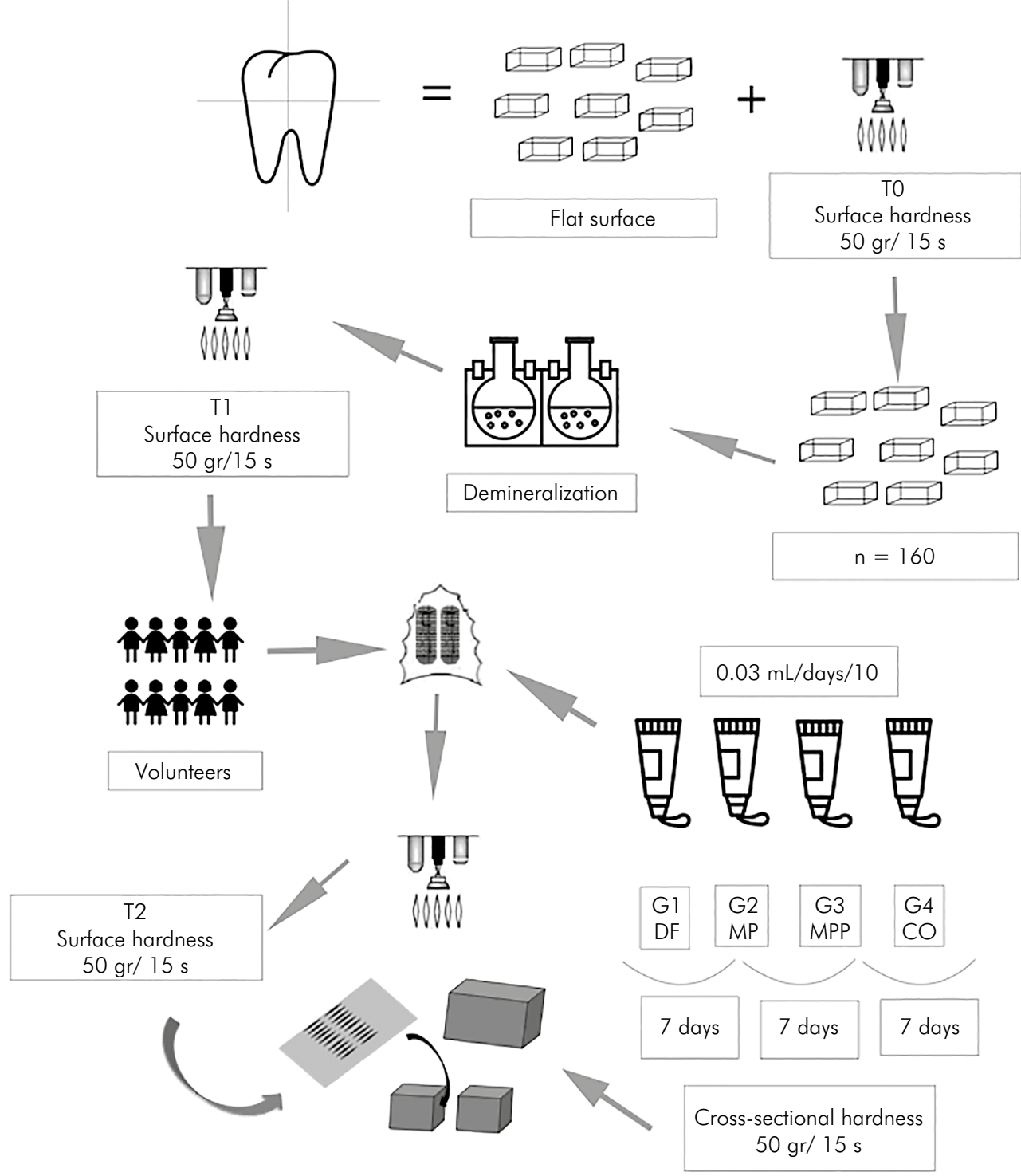

Figure 1. Schematic illustration of the experimental design.

\section{Enamel subsurface demineralization}

Enamel blocks were covered with a protective acid-resistant nail varnish (Colorama; Brazil) applied on the sides (cut surfaces) and on the bottom of each block, except for the enamel surface. After sonication and rinsing with distilled water, the specimens were immersed separately in $10 \mathrm{~mL}$ of unagitated demineralizing solution $[2 \mathrm{Mm} \mathrm{Ca}(\mathrm{Ca}$ $\left(\mathrm{NO}_{3}\right)_{2}, 2 \mathrm{Mm} \mathrm{PO}_{4}\left(\mathrm{KH}_{2} \mathrm{PO}_{4}\right)$, and $75 \mathrm{Mm}$ of acetate at $4.3 \mathrm{pH}] .^{18}$ The demineralizing solution was not replaced during the demineralization period $(72 \mathrm{~h})$. After demineralization, the specimens were rinsed under a steady stream of deionized water. Five indentations separated by a distance of $100 \mu \mathrm{m}$ were made in the central region of each enamel slabs. The average of the five indentations made on each specimen was used as the $\mathrm{SH}$ preformed lesion value $(\mathrm{SH}=\mathrm{T} 1)$. After $\mathrm{SH}$ measurements, the prepared specimens were then stored in $100 \%$ relative humidity at $4^{\circ} \mathrm{C}$ until later use. 


\section{Intraoral phase}

Ten healthy adult volunteers (seven females and three males), aged 21 to 42 years, were chosen to participate in the study according to the criterion of Shen et $\mathrm{al}^{4}$. The data were collected from March to December 2017 at the Dental School of Fluminense Federal University. Patients with systemic diseases, pregnant women or breastfeeding mothers, patients undergoing orthodontic intervention, and those using medication that could affect saliva quality and flow rate were excluded from the study. All subjects were given oral and written information about the aim of the study and about the test dentifrice. All volunteers gave their informed written consent. Participants lived in a city with a fluoridated water supply (0.7 mgF/l). Participants maintained their normal diet and oral hygiene procedures throughout the study. An in situ pilot study with five volunteers was performed to test the efficacy of the in situ model. SH was measured before and after in situ treatment. After that, the sample size was calculated assuming an $80 \%$ power for detecting a $20 \%$ difference between the means of the control and treatment groups at a $5 \%$ significance level. A sample size of 10 participants was required. For the intraoral phase, removable acrylic palatal appliances covering the palate from the first premolar to the last tooth in the arch were manufactured for each participant. The appliances were designed with bilateral troughs $(13 \mathrm{~mm}$ long, $6 \mathrm{~mm}$ wide, $4 \mathrm{~mm}$ deep) cut into the base and designed to house the enamel slabs. Before that, the enamel slabs were washed with distilled water and sterilized by exposure to ethylene oxide vapor for $12 \mathrm{~h} .{ }^{19}$ The enamel slabs were retained by sticky wax to produce a 1-mm-deep trough above the enamel surface, allowing plaque to accumulate and to be retained. A plastic mesh (Plásticos Gonçalves Ltda., São Paulo, Brazil) was put over the block, leaving 1-mm space for plaque accumulation. The participants were instructed not to brush the intraoral device where the samples were placed, nor to take any type of medication containing fluoride, to use only fluoride-free toothpaste (starting 1 week before the study and kept throughout the investigation period), to perform their oral hygiene as they usually did, to wear the intraoral device from 8:00 a.m. to 8:00 p.m. every day, and to remove it only at meal times (when the appliances were removed, they were stored in a sealed moist plastic bag at room temperature) (40). A syringe containing the treatment paste (without identification) was given to the volunteers during the test period. All participants wore the device for $12 \mathrm{~h}$. Every day at 2:00 p.m., the participants had to draw $0.03 \mathrm{~mL}$ into a syringe and apply the solution on the enamel slabs in the acrylic device, rubbing it with their finger and spreading it to allow for its penetration through the plastic mesh. After waiting for $3 \mathrm{~min}$, they were instructed not to remove their appliances for at least $30 \mathrm{~min}$ after each treatment. While wearing the appliance, the participants were instructed not to eat or drink anything. The appliances were cleaned with distilled water only and not over the inset enamel slabs. The participants crossed over to each of the four treatments after at least a 1-week washout period. The participants were supplied with a dentifrice without fluoride. After completion of each treatment period, the enamel slabs were removed from the appliances, rinsed with deionized water, and stored in a humidified environment prior to analysis. The volunteers received intraoral devices with four demineralized enamel slabs in each group. The participants were randomly assigned to one control and three experimental procedures. The randomization was performed through a table generated by a computer program (www.randomizer.org).

\section{Surface hardness}

The sound enamel (T0), subsurface lesion (T1), and post-treatment (T2) measurements were conducted using the same static load and time. The first author performed all measurements (without identification). Five indentations with a $100-\mu \mathrm{m}$ space between T0, T1, and T2 indentations were made with a Knoop diamond indenter under a 50-gram load for $15 \mathrm{~s}$. The percentage recover of $\mathrm{SHr}(\% \mathrm{SH})$ was calculated $[\% \mathrm{SHr}=(\mathrm{T} 2-\mathrm{T} 1) / \mathrm{T} 2 * 100]$.

\section{Cross-sectional hardness}

At the end of the SH test, the enamel specimens were embedded in acrylic resin with the outer enamel surfaces perpendicular to the surface of resin blocks, 
polished as described earlier, and evaluated by cross-sectional microhardness measurements. Two rows of five indentations each were made, one at the center of the exposed dental enamel and one at $100 \mu \mathrm{m}$ from the central row of indentations using a 50 -gram load for $15 \mathrm{~s}$. The indentations were made at $25,50,75,100,125,150,175,200,225$, and $250 \mu \mathrm{m}$ from the outer enamel surface. The mean values of the two measurement points were calculated at each distance from the surface. For the analysis of inhibit demineralization or remineralization patterns, hardness profiles were calculated at each depth by the hardness values for the experimental groups and for the control group. Integrated hardness (KHN $x \mu \mathrm{m})$ for the lesion in the treatment groups was calculated by the trapezoidal rule and subtracted from the integrated hardness for the control group to obtain the integrated area of subsurface regions in enamel, referred to as integrated change of subsurface hardness $(\triangle \mathrm{IHC})$. These values were then converted to $\%$ change $\left[\% \Delta \mathrm{IHC}=\left(\mathrm{IH} \_\right.\right.$treatment $-\mathrm{IH} \_$control $) /$ $\mathrm{IH} \_$treatment $\left.{ }^{*} 100\right]$.

\section{Statistical analysis}

The data and graph were prepared using GraphPad Prism, version 8.0 (GraphPad Software, Inc, San Diego , USA). Initially, all the data were checked by the Shapiro-Wilk test. Based on these preliminary analyses, the data (KHN and \% $\mathrm{SHr}$ ) were subjected to the Kruskal-Wallis and Mann-Whitney tests. KHN before and after treatment in the same groups was analyzed using Wilcoxon's matched-pairs signedrank test. Multiple comparisons using the HolmSidak test were used to evaluate $\mathrm{CSH}$. All analyses were performed at a significance level of $\alpha=0.05$.

\section{Results}

All participants completed the study with 100\% compliance. The participants reported no adverse events. Demineralized lesions (all groups) had similar initial SH prior to exposure to the oral environment. After formation of the preformed lesion (T1), the median KHN was lower and significantly different as compared to T0 in all groups (Figure 2; Wilcoxon's paired t-test; $\mathrm{p}<0.05)$. After treatment $(\mathrm{T} 2)$, the median hardness was high in all groups except for $\mathrm{CO}$ $(p<0.05)$. SH of experimental groups was significantly higher in MPP (median=175.5; 95\%CI = 1 42-211.1), $\mathrm{MP}($ median $=175.4 ; 95 \% \mathrm{CI}=154-195.2)$ and DF (median $=168.9 ; 95 \% \mathrm{CI}=106.4-190.1)$ groups when compared to $\mathrm{CO}($ median $=127.4 ; 95 \% \mathrm{CI}=104-222.1)$, respectively (Figure 2). Figure 3 shows that MP, MPP, and FD groups had a gain of \%SHr after the in situ phase; however, CO had loss of \%SHr (Kruskal-Wallis and Mann-Whitney tests; $p>0.05$ ). Results showed statistical significance for the group and distance factors and for the interaction between group and distance, indicating that the effect of the treatments was different, depending on the depth of the enamel surface. There were significant differences $(p<0.05)$ in lesion depth changes (CSH). When the effect of the treatments was compared with the negative control group $(\mathrm{CO})$ at each distance from the surface, the treatments with MP $(\mathrm{p}<0.02)$ and $\mathrm{FD}(\mathrm{p}<0.01)$ were more effective in reducing enamel demineralization at the 75 and $75-175 \mu \mathrm{m}$ depths, respectively, when compared with CO. The MPP group did not significantly reduce demineralization compared with the CO group $(p>0.05)$ and was not different from the FD and MP groups ( $p>0.05)$. KHN vs. depth from the surface for all groups is shown in Figure 4. Treatment with DF, MP, and MPP reduced the lesion by $20.27 \%, 19.24 \%$, and $14.71 \%$ when compared to CO (Table).

\section{Discussion}

In the present study, demineralized enamel specimens were attached to removable acrylic palatal appliances to investigate the remineralization potential of CPP-ACP/CPP-ACFP-based crèmes in an in situ model. Human enamel blocks with preformed lesions were used to assess remineralization or the inhibition of demineralization. In situ caries models have a vital role in the elucidation of the caries process and in the screening of products containing remineralizing agents. ${ }^{16,1}$. In the current study, MP, FD, and MPP were better at reducing demineralization (caries progression) when compared to the fluoride-free dentifrice (placebo control), thus validating the in situ model used. Therefore, the null hypothesis was rejected. In the in situ model, enamel 


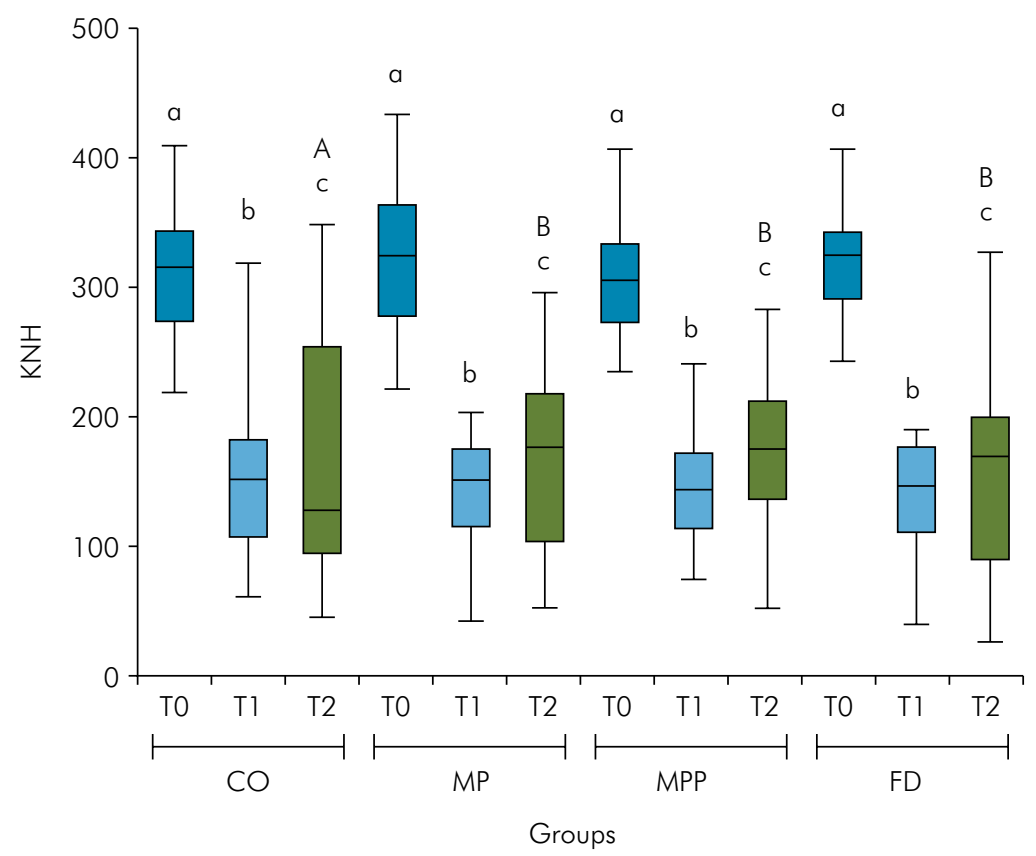

Lowercase letters denote statistical difference between phases in the same group $(p<0.05)$. Uppercase letters denote statistical difference between groups (phase T2; $p<0.05$ ). Wilcoxon's paired t-test; $p<0.05$

Figure 2. Boxplot of the SH for all treatment groups. SH (median with maximum and minimum) in different phases of the study $(\mathrm{TO}, \mathrm{T} 1$, and $\mathrm{T} 2)$.

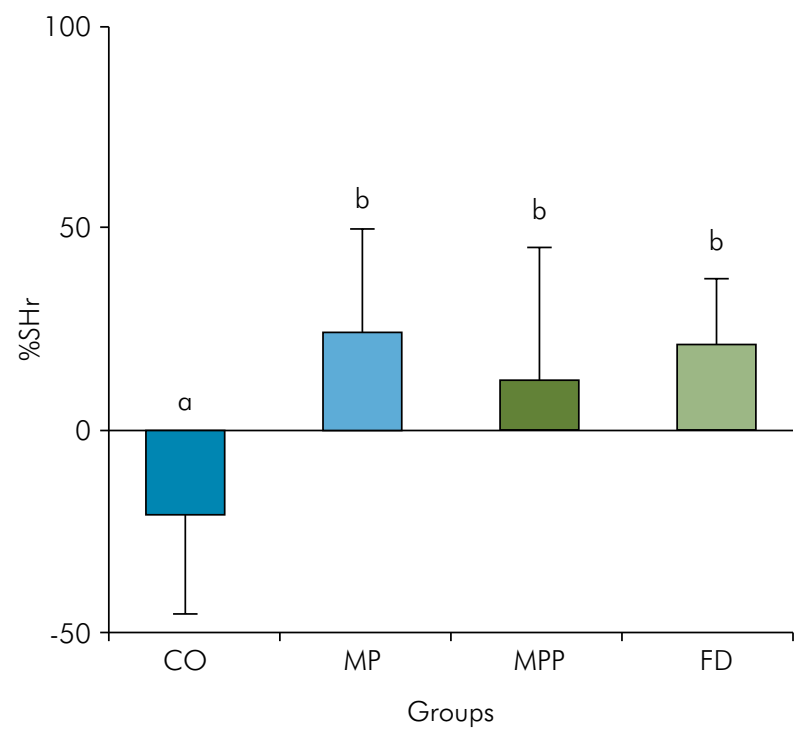

Figure 3. \% Surface hardness recovery (median with 95\% Cl) among groups. Lowercase letters denote statistical difference (Kruskal-Wallis and Mann-Whitney tests; $p>0.05$ ).

blocks with preformed lesions were pulled back $1 \mathrm{~mm}$ from the border of the acrylic appliance and covered with a plastic mesh, allowing for biofilm accumulation and demineralization. ${ }^{3,4,15}$ Our findings indicate that 10 days of study were enough to curb demineralization, but not enough to allow for total remineralization in experimental groups. Other study has demonstrated remineralization at the same time of exposure and with other method of evaluation. ${ }^{4}$ The Knoop hardness method is effective, sensitive, and able to detect mineral losses and gains in both enamel and dentin. ${ }^{16,18,19,20,21}$ In the present study, surface and cross-sectional hardness tests were used to assess changes in demineralized enamel both on its surface and at depth.

In the present study, the application of MP, MMP, and FD significantly prevented demineralization. Therefore, while saliva played a role in remineralization, ${ }^{22}$ hardness did not increase in preformed lesions when placebo dentifrice was used. The findings are in line with those of some other studies. ${ }^{10,16,22}$ However, in some studies, remineralization of the lesion treated with saliva increased with the length of treatment ${ }^{22}$. This suggests that a larger length of study could increase remineralization of the demineralized enamel when exposed to saliva. In the experimental 

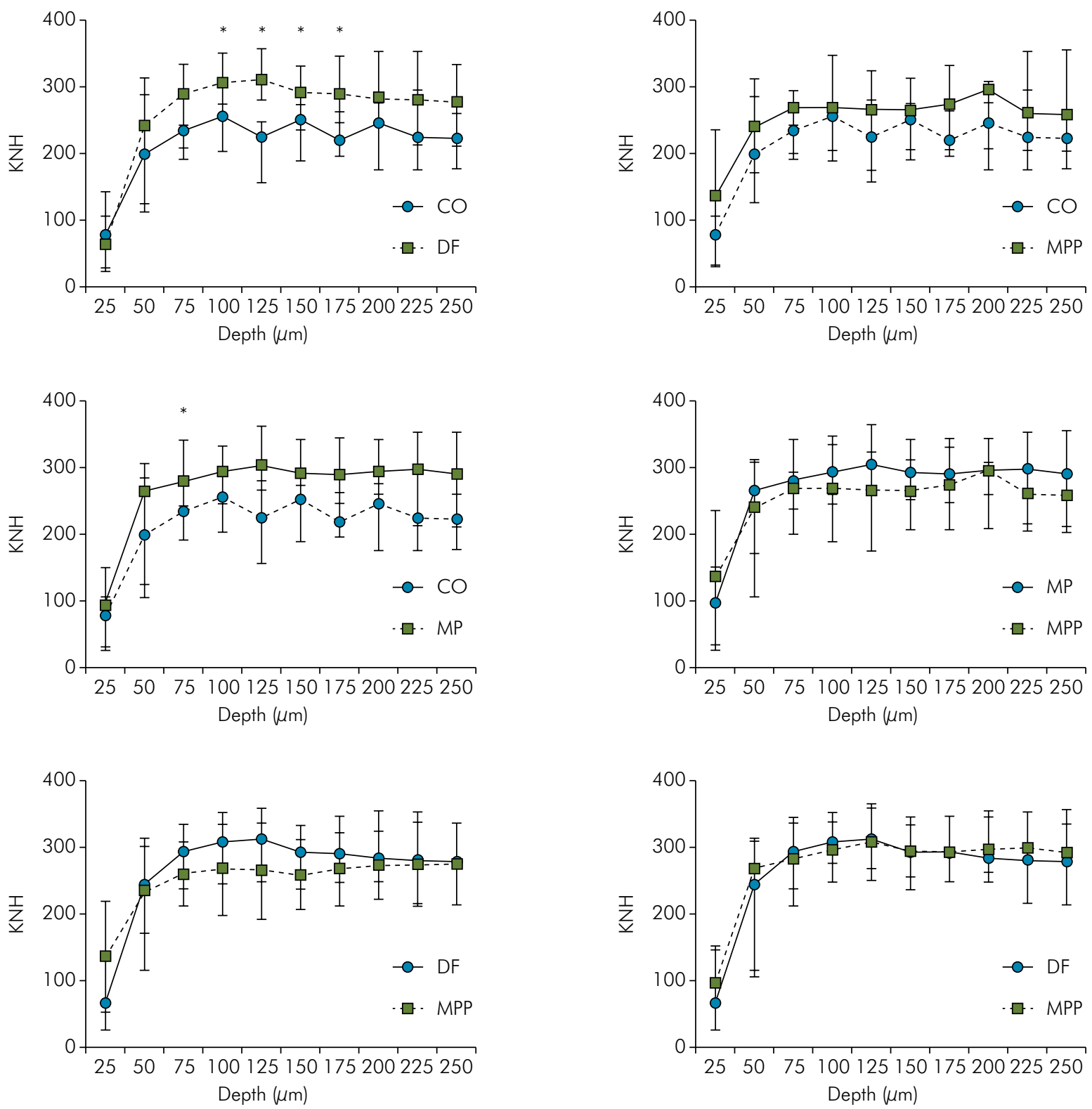

Figure 4. KHN (median and coefficient of variation) at different depths. (*) denotes statistically significant difference between the experimental and control groups $(p<0.05)$.

groups, MPP was the remineralizing agent with the lowest surface hardness gain. This finding is at odds with that of other studies. ${ }^{3,4,15}$ According to Shen et al., ${ }^{3,4}$ larger levels of inorganic phosphate and calcium and, consequently, larger remineralization were found in products containing CPP-ACP when compared to similar products. Shen et al. ${ }^{4}$ also observed higher concentrations of salivary calcium, inorganic phosphate, and fluoride ions when tooth mousse (TM) and tooth mousse +900 ppm F (TMP)
Table. Integrated hardness $(\mathrm{KHN} \times \mu \mathrm{m})$ and integrated change of subsurface hardness $(\Delta \mathrm{HC})$.

\begin{tabular}{lcc}
\hline Groups & $\Delta \mathrm{HH}(\mathrm{KHN} \times \mu \mathrm{m})^{*}$ & $\% \Delta \mathrm{HHC}(\mathrm{KHN} \times \mu \mathrm{m})^{* *}$ \\
\hline $\mathrm{CO}$ & $1959(1731$ to 2188$)$ & - \\
MP & $24(2213$ to 2639$)$ & 19.24 \\
MPP & $2297(2041$ to 2552$)$ & 14.71 \\
FD & 2457 (2229 to 2686$)$ & 20.27 \\
\hline
\end{tabular}

${ }^{*} \mathrm{H}(\mathrm{KHN} \times \mu \mathrm{m})$-Integrated of subsurface hardness (total area$95 \% \mathrm{Cl}) ; * * \% \Delta \mathrm{HC}(\mathrm{KHN} \times \mu \mathrm{m})$ represents the \% change in $\Delta \mathrm{lH}$ values. Lowercase letters denote statistical difference $(p<0.05)$. 
were used, significantly increasing the salivary levels of calcium and inorganic phosphate. TMP had higher saturation than fluoroapatite (FA) because of higher salivary levels of calcium and of inorganic phosphate, as well as of fluoride. The release of calcium and phosphate ions by CPP depends on $\mathrm{pH}$, with an increase in the release of the ions as $\mathrm{pH}$ decreases..$^{15}$ In the presence of fluoride ions, however, CPP releases larger amounts of calcium and phosphate ions at all $\mathrm{pH}$ levels ${ }^{15}$. Hence, the presence of calcium, phosphate, and fluorine in the biofilm was expected to improve the efficacy of MPP as compared to MP, but according to $\mathrm{SH}$ analysis, this association - fluoride and CPP-ACP - was not found in the present study. These findings had already been reported in in vitro studies. ${ }^{10,11,13}$ The lower concentration of fluoride ${ }^{22-24}$ or the lower concentration of available calcium could be the cause for the poor efficiency of ACP-CCPF in remineralization described in in vitro studies. ${ }^{14} \mathrm{We}$ then speculate that the presence of phosphate, which may either compete with fluoride for calcium bonds or precipitate, might have influenced these results. Other studies have shown that another system containing calcium and phosphate and with higher fluoride levels has been more effective in remineralization. ${ }^{14,23,24,25}$ The effect of fluoride ions on remineralization depends on the availability of calcium and phosphate and, thus, products with higher fluoride availability could promote higher remineralization. In the current study, to minimize methodological differences, all products were applied for 3 min once a day, following the MP and MPP manufacturer's instructions. Earlier, we had observed that the higher frequency of application could improve the efficacy of CPP-ACP products., ${ }^{910}$ In addition, MP and FD were statistically different from the control when five 1-minute applications were compared to three 1-minute applications ${ }^{9}$ or to an experimental protocol with a longer duration. ${ }^{22}$ This suggests that the increase in frequency of application ${ }^{9}$ or duration ${ }^{15,22}$ of treatment could prove more advantageous for remineralization.

In our study, all remineralizing agents showed remineralization after treatment, but remineralization was less prominent in the outer enamel layer, regardless of the group. The specimens with preformed lesions were subjected to large cariogenic challenges. Note that the volunteers did not make use of fluoridated dentifrice and did not brush the specimens, which could have contributed to higher remineralization. The presence of fluoride from other sources, such as toothpaste used by the volunteer for toothbrushing, could have had a remineralizing effect and been a confounding factor. ${ }^{16,17,26}$ The volunteers were living in a town supplied with fluoridated water and the release of fluorine by the saliva could have also contributed to the outcomes obtained. However, CSH, FD, and MP were able to inhibit demineralization and/or promote remineralization at a depth of $175 \mu \mathrm{m}$ and $75 \mu \mathrm{m}$, respectively. MP and MPP showed similar results in both analyses. Reynolds ${ }^{1}$ utilized microradiography to assess remineralization and found that CPP-ACP is better than a dentifrice with higher fluoride levels at promoting remineralization of subsurface lesions. These findings differ from those obtained in the present study.

In this study model, we observed that preformed lesions should be treated with a remineralizing agent to inhibit their progression. The control group (no treatment) could not inhibit deep demineralization after 10 days. This is the most important finding of this study. After the in situ phase, there was mild remineralization in $\mathrm{SH}$ in the control group, but the values were lower than those observed in the experimental groups (progression) at all depths. Shen et al. ${ }^{4}$ reported better remineralization of enamel subsurface lesion in situ after Tooth Mousse Plus (TMP) and Tooth Mousse (TM) application than after the use of the fluoride products. According to the authors, the product provided high concentrations of stabilized and bioavailable calcium, phosphate, and fluoride ions in the saliva, promoting remineralization in the body of the lesion. Our results indicate that all products were effective in decreasing demineralization during in situ treatment, but FD was more effective than when no treatment was performed. Although fluoride was present in both fluoride products, the results suggest that an amount of fluoride might be inactive in $\mathrm{MPP}^{13}$. The amount of fluoride release would depend on the differences in solubility and release of fluoride according to the fluoride products. ${ }^{23}$ For products containing CPP-ACP agents, longer periods may be necessary for a more uniform remineralization challenge. 
In the present study, a cross-sectional design and oral hygiene with fluoride-free toothpaste were used to reduce variability, especially regarding individuals and the fluoride available in the oral cavity. In brief, this study took extra care to minimize variability among specimens, and the obtained results are important for understanding the mechanism of action of CPP-ACP. The outcome measures for MI Paste Plus compared to those of the MI Paste group indicate that fluoride application does enhance remineralization, but from a clinical point of view, it was of interest to find that this association, despite the limitations and short duration of this study, was not superior to fluoride toothpaste alone. Remineralizing agents (MP, MPP, and $\mathrm{DF}$ ) were able to inhibit demineralization of human enamel subjected to high cariogenic challenge in situ.
DF had the greatest potential against the progression of carious lesions.

\section{Acknowledgements}

The authors would like to thank José Maria Suhett de Azevedo (Labiom-R) for his assistance with the laboratory equipment. This manuscript was based on a thesis submitted by the first author in partial fulfillment of the requirements for the doctoral degree in Clinical Dentistry. The first author thanks the Brazilian Federal Agency for Support and Evaluation of Higher Education for the scholarship. CMB and LSCB appreciate the scholarships granted by the National Council for Scientific and Technological Development. The authors acknowledge the help received from all volunteers.

\section{References}

1. Reynolds EC. Remineralization of enamel subsurface lesions by casein phosphopeptide-stabilized calcium phosphate solutions. J Dent Res. 1997 Sep;76(9):1587-95. https://doi.org/10.1177/00220345970760091101

2. Reynolds EC, Cai F, Cochrane NJ, Shen P, Walker GD, Morgan MV, et al. Fluoride and casein phosphopeptide-amorphous calcium phosphate. J Dent Res. 2008 Apr;87(4):344-8. https://doi.org/10.1177/154405910808700420

3. Shen P, Walker GD, Yuan Y, Reynolds C, Stanton DP, Fernando JR, et al. Importance of bioavailable calcium in fluoride dentifrices for enamel remineralization. J Dent. 2018 Nov;78(11):59-64. https://doi.org/10.1016/i.jdent.2018.08.005

4. Shen P, Manton DJ, Cochrane NJ, Walker GD, Yuan Y, Reynolds C, et al. Effect of added calcium phosphate on enamel remineralization by fluoride in a randomized controlled in situ trial. J Dent. 2011 Jul;39(7):518-25. https://doi.org/10.1016/i.jdent.2011.05.002

5. Cochrane NJ, Saranathan S, Cai F, Cross KJ, Reynolds EC. Enamel subsurface lesion remineralisation with casein phosphopeptide stabilised solutions of calcium, phosphate and fluoride. Caries Res. 2008;42(2):88-97. https://doi.org/10.1159/000113161

6. Cochrane NJ, Cai F, Huq NL, Burrow MF, Reynolds EC. New approaches to enhanced remineralization of tooth enamel. J Dent Res. 2010 Nov;89(11):1187-97. https://doi.org/10.1177/0022034510376046

7. Walker GD, Cai F, Shen P, Adams GG, Reynolds C, Reynolds EC. Casein phosphopeptide-amorphous calcium phosphate incorporated into sugar confections inhibits the progression of enamel subsurface lesions in situ. Caries Res. 2010;44(1):33-40. https://doi.org/10.1159/000275572

8. Rahiotis C, Vougiouklakis G, Eliades G. Characterization of oral films formed in the presence of a CPP-ACP agent: an in situ study. J Dent. 2008 Apr;36(4):272-80. https://doi.org/10.1016/i.ident.2008.01.005

9. Souza CC, Cury JL, Coutinho TC, Silva EM, Tostes MA. Effect of different application frequencies of CPP-ACP and fluoride dentifrice on demineralized enamel: a laboratory study. Am J Dent. 2014 Aug;27(4):215-9.

10. Oliveira P, Fonseca A, Silva EM, Coutinho T, Tostes MA. Remineralizing potential of CPP-ACP creams with and without fluoride in artificial enamel lesions. Aust Dent J. 2016 Mar;61(1):45-52. https://doi.org/10.1111/adj.12305

11. Miyahira K, Coutinho T, Silva E, Pereira A, Tostes M. Evaluation of CPP-ACP and fluoride on inhibition of human enamel demineralisation: cross-sectional hardness and MicroCT studies. Oral Health Prev Dent. 2017;15(6):549-55.

12. Sinfiteli PP, Coutinho TC, Oliveira PR, Vasques WF, Azevedo LM, Pereira AM, et al. Effect of fluoride dentifrice and casein phosphopeptide-amorphous calcium phosphate cream with and without fluoride in preventing enamel demineralization in a $\mathrm{pH}$ cyclic study. J Appl Oral Sci. 2017 Nov-Dec;25(6):604-11. https://doi.org/10.1590/1678-7757-2016-0559

13. Oliveira PR, Coutinho TC, Portela MB, Paula VC, Tostes MA. Influence of biofilm formation on the mechanical properties of enamel after treatment with CPP-ACP crème. Braz Oral Res. 2017 Nov;31(11):e84. https://doi.org/10.1590/1807-3107bor-2017.vol31.0084

14. Souza SCP, Araújo KC, Barbosa JR Jr, Cancio V, Rocha AA, Tostes MA. Effect of dentifrice containing fTCP, CPP-ACP and fluoride in the prevention of enamel demineralization. Acta Odontol Scand. 2018 Apr;76(3):188-94. https://doi.org/10.1080/00016357.2017.1401658 
15. Cochrane NJ, Shen P, Byrne SJ, Walker GD, Adams GG, Yuan Y, et al. Remineralisation by chewing sugar-free gums in a randomised, controlled in situ trial including dietary intake and gauze to promote plaque formation. Caries Res. 2012;46(2):147-55. https://doi.org/10.1159/000337240

16. Featherstone JD, Zero DT. An in situ model for simultaneous assessment of inhibition of demineralization and enhancement of remineralization. J Dent Res. 1992 Apr;71(Spec No):804-10. https://doi.org/10.1177/002203459207100S02

17. Afflitto J, Schmid R, Esposito A, Toddywala R, Gaffar A. Fluoride availability in human saliva after dentifrice use: correlation with anticaries effects in rats. J Dent Res. 1992 Apr;71(Spec No):841-5. https://doi.org/10.1177/002203459207100S10

18. ten Cate JM, Duijsters PP. Alternating demineralization and remineralization of artificial enamel lesions. Caries Res. 1982;16(3):201-10. https://doi.org/10.1159/000260599

19. Amaral MT, Guedes-Pinto AC, Chevitarese O. Effects of a glass-ionomer cement on the remineralization of occlusal caries: an in situ study. Braz Oral Res. 2006 Apr-Jun;20(2):91-6. https://doi.org/10.1590/S1806-83242006000200001

20. Mellberg JR. Hard-tissue substrates for evaluation of cariogenic and anti-cariogenic activity in situ. J Dent Res. 1992 Apr;71(Spec No):913-9. https://doi.org/10.1177/002203459207100S25

21. Arends J, ten Bosch JJ. Demineralization and remineralization evaluation techniques. J Dent Res. 1992 Apr;71(Spec No):924-8. https://doi.org/10.1177/002203459207100S27

22. Oliveira GM, Ritter AV, Heymann HO, Swift E Jr, Donovan T, Brock G, et al. Remineralization effect of CPP-ACP and fluoride for white spot lesions in vitro. J Dent. 2014 Dec;42(12):1592-602. https://doi.org/10.1016/i.jdent.2014.09.004

23. Karlinsey RL, Mackey AC, Stookey GK, Pfarrer AM. In vitro assessments of experimental NaF dentifrices containing a prospective calcium phosphate technology. Am J Dent. 2009 Jun;22(3):180-4.

24. Elkassas D, Arafa A. Remineralizing efficacy of different calcium-phosphate and fluoride based delivery vehicles on artificial caries like enamel lesions. J Dent. 2014 Apr;42(4):466-74. https://doi.org/10.1016/i.ident.2013.12.017

25. Alkattan R, Lippert F, Tang Q, Eckert GJ, Ando M. The influence of hardness and chemical composition on enamel demineralization and subsequent remineralization. J Dent. 2018 Aug;75(5):34-40. https://doi.org/10.1016/i.jdent.2018.05.002

26. Bröchner A, Christensen C, Kristensen B, Tranæus S, Karlsson L, Sonnesen L, et al. Treatment of post-orthodontic white spot lesions with casein phosphopeptide-stabilised amorphous calcium phosphate. Clin Oral Investig. 2011 Jun;15(3):369-73. https://doi.org/10.1007/s00784-010-0401-2

27. Philip N. State of the Art Enamel Remineralization Systems: The Next Frontier in Caries Management. Caries Res. 2019;53(3):284-95. https://doi.org/10.1159/000493031 